\title{
Exploration and Practice of a New Training Mode for Innovative and Entrepreneurial Talents of Information Security
}

\author{
Jun Zhao* and Lei Shi
}

\author{
Chengdu University of Information Technology \\ *Corresponding author. Email: zhaojun@cuit.edu.cn
}

\begin{abstract}
In order to meet the national demand for the cultivation of innovative and entrepreneurial talents, this paper analyses the characteristics of the current information security major and the current situation of the cultivation of innovative and entrepreneurial talents, and proposes the construction of a "six in one" talent training platform and a new "entrepreneurship and innovation" talent training mode based on the platform. This mode breaks the traditional education mode, and is conducive to the promotion of the ability of "mass entrepreneurship and innovation" and the cultivation of "double innovation" talents of information security major, and can be applied to the process of cultivating "double innovation" talents of other related majors. It plays a positive role in comprehensively deepening the reform of innovation and entrepreneurship education in Colleges and universities, and accelerating the cultivation of talents to meet the development needs of innovative countries In addition, it is necessary to improve the quality of the products.
\end{abstract}

Keywords: Entrepreneurship and innovation, Information security, Six in one, Talent training.

\section{TRAINING DEMAND OF INNOVATIVE AND ENTREPRENEURIAL TALENTS}

In the current personnel training mechanism of colleges and universities, the cultivation of innovative and entrepreneurial talents should be an important part, which plays an important role in the current economic and social development of our country. As the training center of all kinds of talents, colleges and universities are also an important platform for innovation and entrepreneurship education. Under the current "Internet plus double creation" background, we should focus on training the innovative spirit, entrepreneurial awareness and entrepreneurial ability of students majoring in information security.

\section{THE CURRENT SITUATION OF INNOVATIVE AND ENTREPRENEURIAL TALENTS TRAINING OF INFORMATION SECURITY SPECIALTY}

Information security is a relatively new major, and it is also an important specialty of Cyberspace Security discipline. It has been set up in many specialties in China. The specialty has certain characteristics and has special requirements for the allocation of innovative and entrepreneurial talents. Through the investigation and analysis of the current situation of the cultivation of the "mass entrepreneurship and innovation" talents in this major in recent years, it is found that there are some problems in the training process, which are specifically manifested in the following aspects:

\subsection{The Practical Ability of Students has not been Improved}

The traditional teaching mode has instilled certain theoretical knowledge for the students, but the practical ability of students has not been improved, especially the team cooperation level is low, the competition experience is not enough, and the actual combat level of attack and defense needs to be improved. 


\subsection{The Current Teaching Program cannot Meet the Needs of Professional Development}

With the rapid development of disciplines, individual professional content has gradually become the focus of domestic and international attention. But the professional training program can not quickly respond to the needs of information security development, the combination of theory and practice is more disjointed.

\subsection{The Training Requirements are not well Implemented}

In the process of personnel training, the requirements for the cultivation of entrepreneurship and innovation talents are not well implemented. Students cannot master and understand the contents of entrepreneurship and innovation well, and do not pay enough attention to the process of entrepreneurship and innovation.

In this paper, a new "double innovation" talent training mode of information security specialty is proposed, which includes the reconstruction of talent training scheme, the construction of practical teaching system, the formation and cultivation of student teams, the guidance of innovation and entrepreneurship projects and the driving of discipline competition, the construction of school enterprise cooperation platform, the collaborative innovation of industry, University and Research Institute, and the construction of innovation and entrepreneurship platform Reform.

\section{MAIN RESEARCH CONTENTS}

\subsection{Reconstructing the Training Scheme of Entrepreneurship and Innovation Talents}

Through widely soliciting the opinions of industry experts and scholars, the analysis report of mainstream and cutting-edge technology of information security specialty is formed through investigation. Combined with the characteristics of the specialty and the current situation of personnel training, we reconstruct the training scheme of the innovative and innovative talents and construct the practical teaching system of the cultivation of the ability of entrepreneurship and innovation. Through the investigation of the current mainstream cutting-edge technology of information security major, we actively and effectively improve the training program and syllabus, enhance the publicity of the content and policy of students' Entrepreneurship and innovation, and guide students to learn some interdisciplinary courses under the premise of the requirements of entrepreneurship and innovation, so as to make technical and theoretical preparation for individual and team innovation and entrepreneurship. At the same time, through the guidance of the school and college, it can provide superior system support for college students' innovation and innovation, and give certain credit rewards for college students' entrepreneurial team.

\subsection{Construction of Practical Teaching System for Cultivating the Ability of Entrepreneurship and Innovation}

Practice teaching system should be composed of practice teaching content, quality management, teaching environment support and so on. As shown in Figure 1.

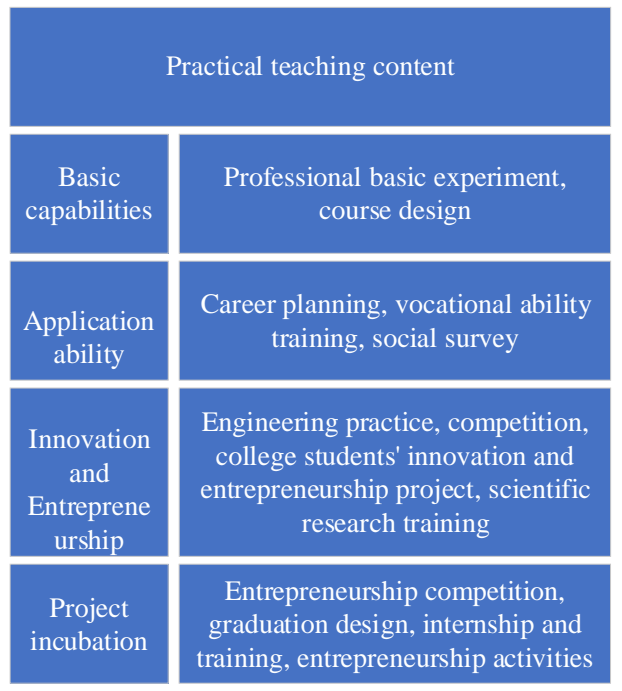

Figure 1 Composition of practical teaching system for cultivating the ability of entrepreneurship and innovation.

The whole training process is divided into four stages to complete the comprehensive training of students' professional skills and entrepreneurship and innovation quality. The first stage mainly requires students to complete the study of professional basic theory; the second stage allows students to participate in the team or some social practice process to improve personal professional skills; the third stage allows students to participate in different team division of labour through team project system, making full use of personal professional skills to complete the project requirements and understand the process of the project, And participate in team communication, assistance, management and other activities, if conditions permit, can participate in more competitions; in the fourth stage, use the incubation platform to complete the incubation of team projects, and actively create the characteristics of the project, and strive for some external investment.

\subsection{Building a Sustainable Team}

To build a "help and guide" team of students' Entrepreneurship and innovation, so as to continuously 
improve the practice of innovation and entrepreneurship projects

Analyse the characteristics of different grades of students, create a "help and guide" students' Entrepreneurship and innovation team, and form a cultivation mode from learning theoretical basis, improving personal skills, participating in project competitions and independent innovation and entrepreneurship. The team pays attention to the accumulation of skills and experience in the practice of innovation and entrepreneurship projects, so that successful innovation and entrepreneurship projects can be continuously upgraded.

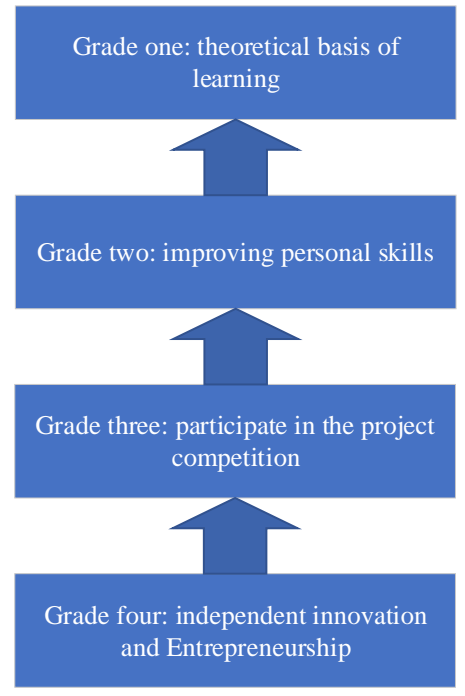

Figure 2 Cultivation mode of "teaching, helping and leading" students' Entrepreneurship and innovation team.

\subsection{Participating in Competitions and Projects}

We improve students' creativity by participating in projects and competitions.

In the process of training, we should pay attention to the guidance of the project, and complete the design, development, packaging, publicity and other activities of the project in a team way, so that students can give full play to their professional strengths and skills, make personal contributions to the team, stimulate students' innovative consciousness, and create the characteristics and innovation points of the project. When the conditions are mature, we can participate in some competitions inside and outside the school through the completed projects, so as to enhance the students' innovative thinking and broaden the innovative vision of the project team.

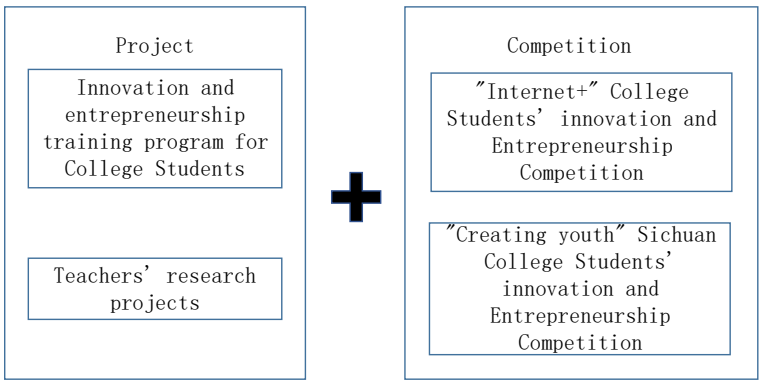

Figure 3 Innovation and entrepreneurship project guidance and discipline competition driven mode.

\subsection{School Enterprise Cooperation and Industry University Research Collaboration}

We pay attention to the construction of school enterprise cooperation platform and collaborative innovation of industry, University and Research Institute.

The cooperation of information security enterprises in the construction of information security platform, joint curriculum reform, strengthening teacher training and other collaborative innovation measures. Joint wellknown information security enterprises to jointly create various information security platforms, such as attack and defense drill platform, penetration test platform, information security teaching platform, etc. Through the construction and application of the platform, we can solve the problem that students' actual combat ability is not enough and their innovation consciousness cannot be improved. Through the way of industry university cooperation and collaborative education, improve the practical conditions, joint curriculum reform, enhance teacher training, let students into the enterprise, so that the urgent needs of enterprises become the driving force of students' innovation.

\subsection{Entrepreneurship Platform and Innovation and Entrepreneurship Project}

We build a business platform to cultivate students business ability. In our training scheme, we set up a two-level entrepreneurship platform of the University and college to enhance the business ability and business awareness of the students, and invite enterprise and public servants to train the students in the aspects of bidding document writing, bidding, project management, acceptance, patent application, financial management, etc., so as to supplement the business weakness of science college students and solve the pain points in the process of entrepreneurship and innovation training. Guide the innovation and entrepreneurship student team to carry out the continuous practice and competition of innovation and entrepreneurship projects. Through the two-level innovation and entrepreneurship platform of colleges and universities, 
we cultivate many successful innovation and entrepreneurship projects, and actively carry out entrepreneurship and business-related courses training for student teams. Relying on the science and Technology Innovation Incubation Park, create 1-2 "Star" innovation and entrepreneurship projects.

\section{PRACTICE AND ACHIEVEMENTS}

In recent years, through the construction of a "six in one" talent training platform for information security major and the practice of the new "entrepreneurship and innovation" talent training mode based on the platform, our team has led the students to achieve a lot of teaching results, mainly including:

1. Guide the student team to win awards in innovation and entrepreneurship projects:

(1) The first "China Internet+ Sichuan innovation and entrepreneurship competition" bronze medal.

(2) The third prize of the third "creating youth" Sichuan Youth Innovation and Entrepreneurship Competition

(3) The third prize of the 9th National Undergraduate e-commerce innovation and Entrepreneurship Challenge competition

2. The team has obtained 5 projects approved by the Ministry of education for industry university cooperation

3. In the latest version of the information security personnel training program, the college highlights the training objectives and specific curriculum setting of entrepreneurship and innovation talents.

4. The college has successfully held the national information security competition for many years, and has a high reputation in the field of domestic information security.

5. The student team has won 3 national level largescale innovation projects.

6. Teacher has guided four student teams to settle in Science and technology innovation incubator of Chengdu University of information technology, and obtain the start-up fund support of entrepreneurship projects.

\section{CONCLUSION}

Through the exploration and practice of the new training mode of innovative and entrepreneurial talents of information security specialty, the construction of a six in one talent training platform and the new "double innovation" talent training mode based on the platform has very important significance and research value for the cultivation of "double innovation" talents of information security specialty, which can be used as a research reference for the cultivation of "double innovation" talents of other majors.

\section{AUTHORS' CONTRIBUTIONS}

Jun Zhao: Manuscript preparation, editing, review. Guarantor of intergrity of the entire study. Lei Shi: Guarantor of intergrity of the entire study.

\section{ACKNOWLEDGMENTS}

We gratefully acknowledge the valuable cooperation of Science and technology innovation incubator of Chengdu University of information technology and would like to thank Dr. SaYing Wo for his invaluable contributions during this collaboration.

\section{REFERENCES}

[1] Qian Xiaoming, Rong Huawei, Qian Jingzhu, Practice and thinking of education of "College Students' Innovative and Entrepreneurial Training Program" based on tutor system, Experimental Technology and Management, 2014-07

[2] Paul Herbig, James E. Golden, Steven Dunphy, The Relationship of Structure to Entrepreneurial and Innovative Success, Marketing Intelligence \& Planning, $1994 / 10 / 01$ DOI:10.1108/02634509410069038.

[3] Hanny N. Nasution, Felix T. Mavondo, Margaret Jekanyika Matanda, Nelson Oly Ndubisi, J-P. Katoen, Entrepreneurship: Its relationship with market orientation and learning orientation and as antecedents to innovation and customer value, Industrial Marketing Management, 2011. DOI:10.1016/j.indmarman.2010.08.002.

[4] QUAN Lei, JIANG Nian-de, Relying on Competition to Promote Educational Reform and Cultivate Innovative and Entrepreneurial Talents, Journal of East China University of Technology(Social ence), 2018-04

[5] CHEN Hao, MING Zhong, XIAO Zhijiao, Practice Teaching Reform for the Cultivation of Innovative and Entrepreneurial Capacity, Experiment Science and Technology, 2014-02

[6] Zhefeng Yin, Jinxiang Wang, Research on Entrepreneurship and Innovative Talents Training Mode in Computer Majors Against the Background of New Engineering, 3rd International Conference on Culture, Education and Economic Development of Modern Society (ICCESE 2019)

[7] Ye Mao, Deng Maocheng, Gu Zongzhu, Li Jing, Construction of the Innovative and Entrepreneurial 
Practice Teaching System of Higher Vocational Colleges_-A Case Study of Biochemical Technology Major, Guangdong Chemical Industry, 2016-20 